\title{
Development of a Flow through Photo-Reactor to Study Degradation of Organic Compounds by Sequential Injection Analysis (SIA)
}

\author{
Allan C. V. dos Santos and Jorge C. Masini* \\ Instituto de Química, Universidade de São Paulo, CP 26077, 05513-970 São Paulo-SP, Brazil
}

\begin{abstract}
Este trabalho descreve um foto-reator para a execução "in line" da degradação de compostos orgânicos através da reação de foto-Fenton, utilizando-se de um sistema de Análise por Injeção Sequencial (SIA). Uma solução do corante do sal tetrassódico de ácido 3,4',4",4"'-tetrassulfônico de ftalocianina de cobre foi empregada como modelo da família das ftalocianinas, cujos pigmentos apresentam grande utilização na indústria de tintas automotivas. Baseando-se em testes preliminares, uma remoção de cor de $97 \%$ foi obtida em uma solução contendo $20 \mu \mathrm{mol} \mathrm{L}^{-1}$ deste corante.
\end{abstract}

This work describes a photo-reactor to perform in line degradation of organic compounds by photo-Fenton reaction using Sequential Injection Analysis (SIA) system. A copper phthalocyanine$3,4^{\prime}, 4^{\prime \prime}, 4^{\prime \prime \prime}$-tetrasulfonic acid tetrasodium salt dye solution was used as a model compound for the phthalocyanine family, whose pigments have a large use in automotive coatings industry. Based on preliminary tests, $97 \%$ of color removal was obtained from a solution containing $20 \mu \mathrm{mol} \mathrm{L}-1$ of this dye.

Keywords: photo-Fenton reactor, sequential injection analysis, wastewater, copper phthalocyanine dye, automotive coatings industry.

\section{Introduction}

Oxidative destruction of chemicals provides ultimate solutions for the treatment of hazardous wastes ${ }^{1}$. Advanced Oxidative Processes (AOP's) are based on the generation of the hydroxyl radical, ${ }^{\circ} \mathrm{OH}$, a species that acts as a strong oxidant to a wide variety of organic and inorganic compounds ${ }^{2}$. A special kind of AOP is the Fenton reaction, ${ }^{3}$ in which the hydroxyl radical is formed from the reaction between $\mathrm{H}_{2} \mathrm{O}_{2}$ and $\mathrm{Fe}(\mathrm{II})$ ions. This reaction can also be processed under influence of ultraviolet radiation, leading to the so-called photo-Fenton reaction. The Fenton and related reactions are viewed as potentially convenient and economical ways to generate oxidizing species for treating chemical wastes; compared to other bulk oxidants, hydrogen peroxide and iron are inexpensive, safe, and environmentally friendly ${ }^{4}$. AOP's are particularly interesting for non-biodegradable compounds that can be recalcitrant and/or toxic to microorganisms ${ }^{5}$.

Flow techniques are being consolidated as powerful tools for the routine control of parameters in various samples of environmental origin ${ }^{6}$. Sequential Injection

*e-mail: jcmasini@iq.usp.br
Analysis (SIA), a flow technique proposed by Ruzicka and Marshall, ${ }^{7}$ can be used to perform experiments necessary for the optimization of industrial processes ${ }^{8}$. The purpose of this paper is to describe an UV reactor specifically designed to study photo-Fenton reactions with a SIA system. A solution of copper phthalocyanine dye was used as a model compound for the phthalocyanine family, whose pigments may be present in effluents of automotive coatings industry.

\section{Experimental}

\section{Reagents}

All reagents were of analytical grade and the working solutions were prepared in deionized water obtained from a Simplicity 185 system from Millipore coupled to an UV lamp (Millipore, São Paulo, SP, Brazil).

Copper phthalocyanine dye, specifically copper phthalocyanine- $3,4^{\prime}, 4^{\prime \prime}, 4^{\prime \prime \prime}$-tetrasulfonic acid tetrasodium salt, molecular formula $\mathrm{C}_{32} \mathrm{H}_{12} \mathrm{CuN}_{8} \mathrm{O}_{12} \mathrm{~S}_{4} \cdot 4 \mathrm{Na}$ (CAS 123439-80-5) and molar mass of $984.25 \mathrm{~g} \mathrm{~mol}^{-1}$ was acquired from Sigma (Sigma-Aldrich Brazil, São Paulo, SP). A $40 \mu \mathrm{mol} \mathrm{L}^{-1}$ solution of the dye was prepared only 
by dilution of the salt with deionized water, adjusting the $\mathrm{pH}$ to 2.5 by adding $\mathrm{HNO}_{3}$.

Iron sulfate solution was prepared by dissolving $\mathrm{FeSO}_{4} \cdot 7 \mathrm{H}_{2} \mathrm{O}$ salt with deionized water and $\mathrm{HNO}_{3}$ to obtain a final concentration of $80 \mu \mathrm{mol} \mathrm{L}^{-1}(\mathrm{pH} 2.5)$ and then purged with $\mathrm{N}_{2}$ and protected from atmospheric $\mathrm{O}_{2}$, thus avoiding rapid oxidation of $\mathrm{Fe}(\mathrm{II})$.

Hydrogen peroxide solution at concentration of $0.5 \mathrm{mmol} \mathrm{L}^{-1}$ was prepared by direct dilution of commercial stock solution with deionized water and $\mathrm{HNO}_{3}$ to a final $\mathrm{pH}$ of 2.5.

\section{Apparatus and procedure}

\section{Reactor design}

The photo-reactor used in the experiments reported herewith was designed in the author's laboratory and the steel structure was manufactured under request by SCA Serviços e Caldeiraria (Ribeirão Pires, SP, Brazil). Figure 1A presents the cover (lid) portion of the reactor and Figure 1B describes the body of the reactor, both made of steel. Basically, a mercury lamp is introduced in the center of the lid hole; more precisely, a $9 \mathrm{~cm}$ long quartz bulb of a high pressure mercury vapour source obtained from a common street lightning fluorescent lamp (Osram HQL E40, $400 \mathrm{~W}$ ) by cutting and removing the larger external fluorescent bulb. Similar use of street lamps for a FIA reactor was already reported by Cavicchioli and Gutz'. An "U" shaped quartz tube $(0.4 \mathrm{~cm}$ o.d., $0.3 \mathrm{~cm}$ i.d., $35 \mathrm{~cm}$ height) was placed inside both cylindrical paths of the cover. Placement of $5 \mathrm{~cm}$ of the tube over the lid base allows connection with SIA/detector tubes; the remaining of the tube $(30 \mathrm{~cm})$ is positioned inside the illuminated area of the reactor. Two Tygon tubes of distinct internal diameters allowed the connection of the $0.8 \mathrm{~mm}$ i.d. Teflon (PolyTetraFluoroEthylene, PTFE) tube from the SIA system to the reactor and from the reactor to the flow cell of the spectrophotometer. The first Tygon tube $(0.3 \mathrm{~cm}$ o.d., $0.1 \mathrm{~cm}$ i.d., $1.3 \mathrm{~cm}$ length) is partially inserted $(0.3 \mathrm{~cm})$ on the second Tygon Tube $(0.4 \mathrm{~cm}$ o.d., $0.3 \mathrm{~cm}$ i.d., $2.3 \mathrm{~cm}$ length) and acts as an intermediate connection. This is necessary because it was empirically observed that a direct connection of a low i.d. PTFE tube to a large i.d. quartz tube leads to air bubbles disruption. Changing the internal diameter (with Tygon connections) and after changing the character of the walls (hydrophobic/ hydrophilic), however, leads to stable air bubbles for a wide range of air plugs and flow rates.

An electric fan (Roxline cooler 065.0004.90006) was fitted to the base of the reactor to force air circulation from its bottom, exiting through the curved slit at the cover, and keeping a stable temperature near the quartz tube region.

Externally, the reactor was coated with a commercial low gloss black primer. Because the internal reactor walls are very reflective, the final internal portion of reactor body (from the fan area to the initial curvature of the reactor base) was also coated with the primer to reduce UV scattering to the environment. Figure 2 shows images of the cover apparatus (Fig. 2A) and the reactor final assembly (Fig. 2B).

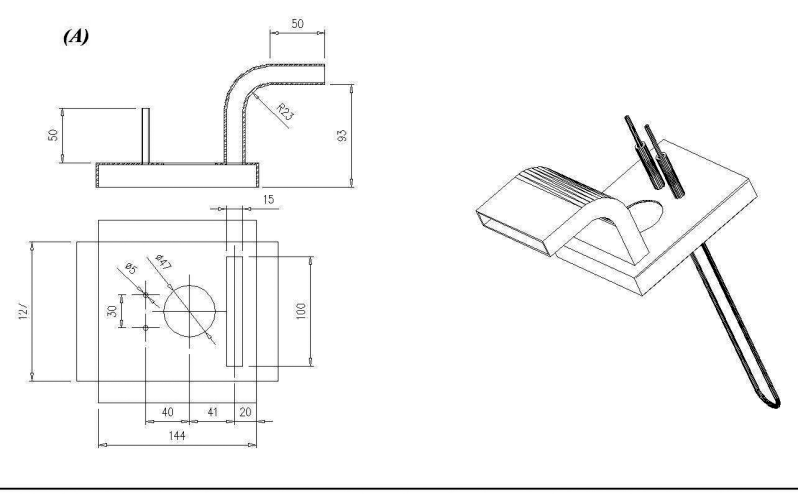

(B)

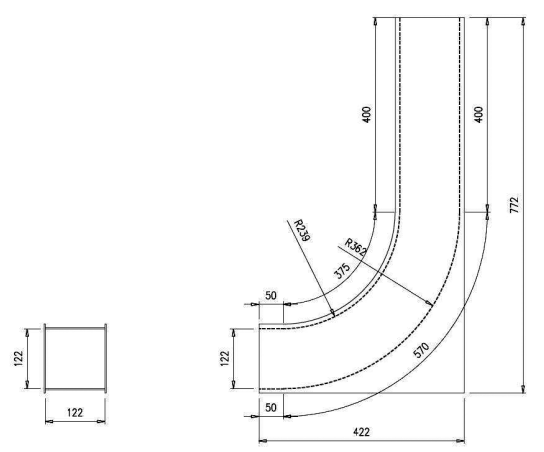

Figure 1. Photo-reactor project description. All values are in millimeters. A - Reactor cover. B - Reactor body.

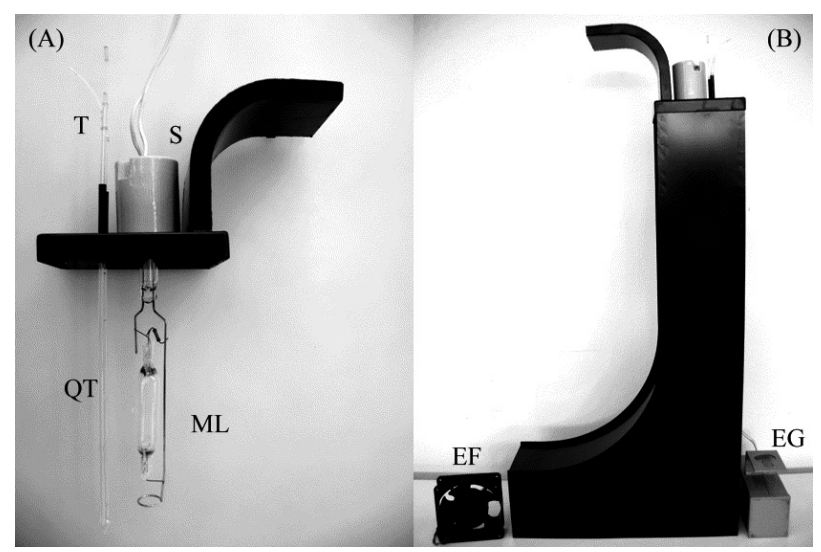

Figure 2. Photo-reactor images. (A) Cover apparatus with quartz tube (QT), mercury street lamp without bulb (ML), Tygon (T) connections and lamp socket (S). (B) Final reactor assembly showing lamp electric control gear (EG) and electric fan (EF) out of the reactor body for clarity. 


\section{SIA manifold}

A FIAlab 3500 system (FIAlab Instruments, Bellevue, WA, USA) was used in the sequential injection mode according to Figure 3. Solutions were driven by a $5.00 \mathrm{~mL}$ syringe pump, SP, and an eight port rotary valve, RV (Valco Instrument Co., Houston). The holding coil, HC, was made of $3 \mathrm{~m}$ of $0.8 \mathrm{~mm}$ i.d. Teflon (PolyTetraFluoroEthylene, PTFE) tubing. Connection from the reactor to the flow detection cell was $53.5 \mathrm{~cm}$ long; connection from port 1 to the reactor was $42 \mathrm{~cm}$ long; both were made of $0.8 \mathrm{~mm}$ i.d. PTFE tubing. All other tubing connections were made of $0.8 \mathrm{~mm}$ i.d. PTFE tubing and PTFE nuts and ferrules (Upchurch, Oak Harbor, WA, USA). A Micronal B382 spectrophotometer (Micronal, São Paulo, SP, Brazil) was used as detector fitted to a $10 \mathrm{~mm}$ light path length flow cell with $80 \mu \mathrm{L}$ of internal volume from Hellma (Hellma GmbH\& Co. Mülheimheim, Baden, Germany), performing absorbance measurements at $632 \mathrm{~nm}$. Spectral curve was previously obtained in a Hitachi spectrophotometer model U-3000 using a quartz batch cell of $10 \mathrm{~mm}$ optical path length.

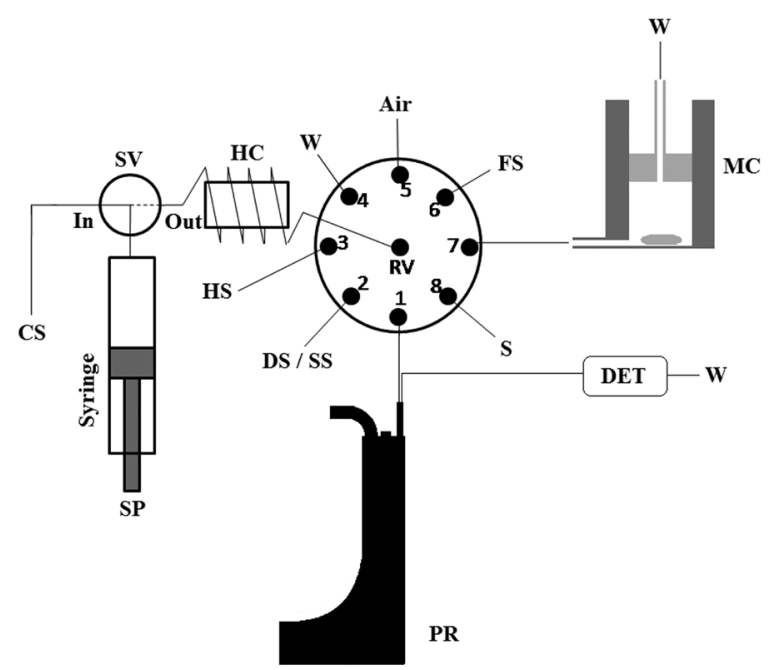

Figure 3. Sequential Injection Analysis (SIA) manifold for photoFenton studies. SP = Syringe pump; SV = selection valve for "in" and "out" positions of the system; HC $=$ holding coil ( 3 meters long, $0.8 \mathrm{~mm}$ of internal diameter); $\mathrm{CS}=$ carrier solution (deionized water); DET $=$ spectrophotometric detector; $\mathrm{MC}=$ mixing chamber (acrylic, with adjustable internal volume) containing magnetic stirrer; $\mathrm{FS}=80 \mu \mathrm{mol} \mathrm{L}-1 \mathrm{FeSO}_{4}$ solution; $\mathrm{HS}=0.50 \mathrm{mmol} \mathrm{L}{ }^{-1} \mathrm{H}_{2} \mathrm{O}_{2}$ solution; $\mathrm{W}=$ waste $; \mathrm{PR}=$ photo-reactor (connections to power supply not shown); $\mathrm{SS}=$ phthalocyanine standard solutions (calibration mode); DS = dilution solution (diluted $\mathrm{HNO}_{3}-\mathrm{pH} 2.5$ ); $\mathrm{S}=40 \mu \mathrm{mol} \mathrm{L} \mathrm{L}^{-1}$ phthalocyanine solution. All solutions (except carrier) were adjusted to $\mathrm{pH} 2.5$ with $\mathrm{HNO}_{3}$.

The SIA system starts the on line sampling of solutions using the monosegmented flow analysis approach ${ }^{10}$. Monosegments aspirated to the holding coil are directed to a mixing chamber for homogenization. Sample, reagents and diluted $\mathrm{HNO}_{3}$ are mixed to give a final solution containing $20 \mu \mathrm{mol} \mathrm{L} \mathrm{L}^{-1}$ of phthalocyanine at $\mathrm{pH} 2.5$, $140 \mu \mathrm{mol} \mathrm{L}{ }^{-1}$ of $\mathrm{H}_{2} \mathrm{O}_{2}$ and $14 \mu \mathrm{mol} \mathrm{L} \mathrm{L}^{-1}$ of $\mathrm{FeSO}_{4}$. Another $1.0 \mathrm{~mL}$ monosegment containing the reaction mixture of the mixing chamber is aspirated by the SIA system and then pumped toward the photo-reactor and stopped for degradation. After the irradiation time, the monosegment is driven to the spectrophotometer for absorbance reading under stopped flow conditions on the 'plateau' between the two sharp peaks generated by the air bubbles passing through the detector. Cleaning of the manifold is performed automatically by the SIA equipment by pumping the carrier (deionized water) through the system.

\section{Results and Discussion}

\section{General performance of photo-reactor}

The temperature profile and time for temperature stabilization of the photo-reactor were studied before performing the blue dye degradation. Using an I.R. thermometer and measuring the reactor wall temperature after $20 \mathrm{~min}$ it was possible to define the temperature profile (Figure 4); by measuring the temperature time dependence of the hottest region (12 $\mathrm{cm}$ below the cover), it was observed that the equipment can reach a stable temperature profile after 15 min (stabilization time) as shown in Figure 5.

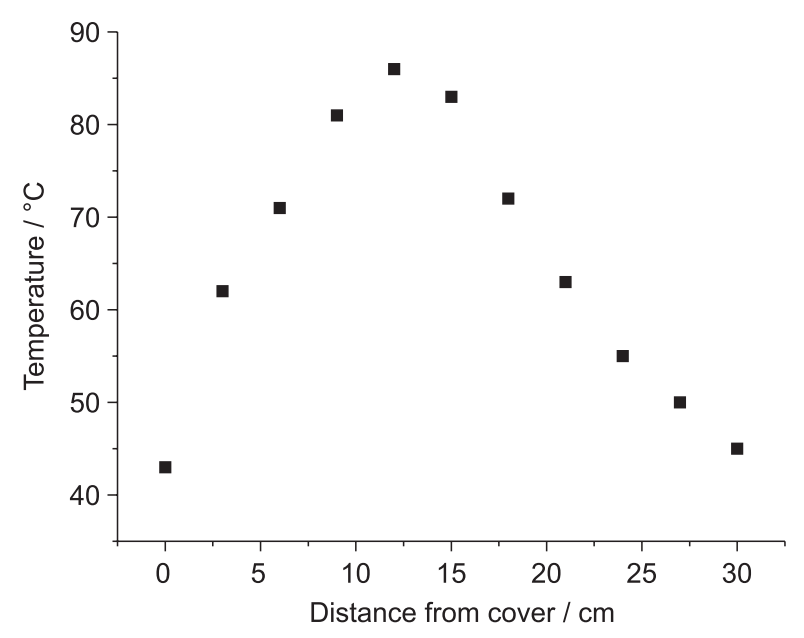

Figure 4. Temperature profile at the walls of the reactor after $20 \mathrm{~min}$ of operation. Distance is measured from the cover to the base of the reactor body.

Measurement with an ordinary mercury thermometer of water temperature exiting the reactor showed that the system can reach temperature equilibrium between carrier and equipment in less than $15 \mathrm{~s}$. This fast equilibration time is possible due to the high area / volume ratio of the quartz tube. Water temperature was found to be around $60^{\circ} \mathrm{C}$, 
Table 1. Experimental conditions employed to evaluate the effect of the photo-reactor on decolorization of phthalocyanine blue

\begin{tabular}{lccc}
\hline Experiment & Experimental Conditions & Stopped Flow in Photo-Reactor / s & Mean absorbance of the monosegment \\
\hline 1 & Photo-reactor off; No Fenton reagent added & 0 & $0.67 \pm 0.02$ \\
2 & Photo-reactor off; Fenton reagent added & $0.61 \pm 0.01$ & 15 \\
3 & Photo-reactor on; Fenton reagent added & 30 & $0.05 \pm 0.01$ \\
4 & Photo-reactor on; Fenton reagent added & $0.02 \pm 0.01$ \\
\hline
\end{tabular}

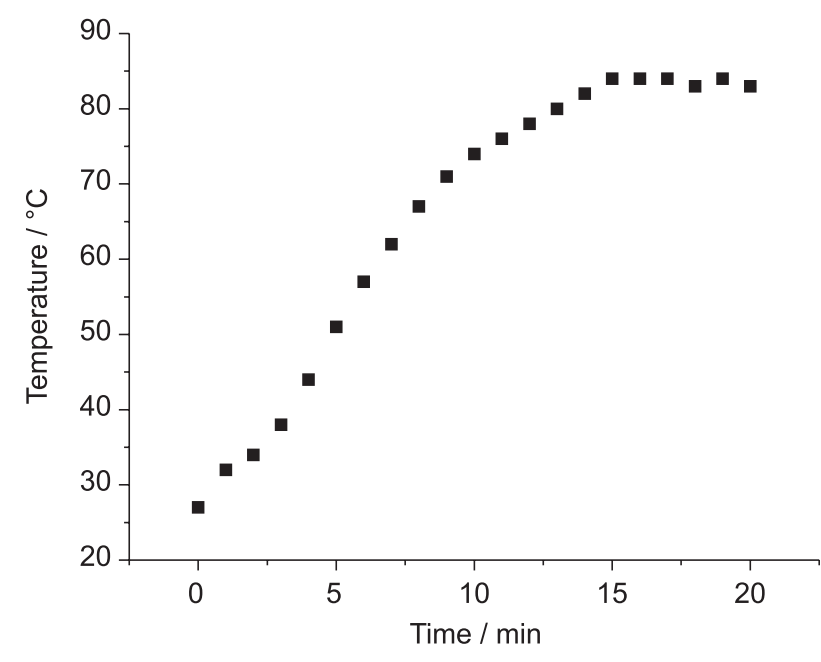

Figure 5. Temperature profile dependence with time monitored $12 \mathrm{~cm}$ below the reactor cover (at the walls of the reactor).

corresponding to approximately the mean temperature in the reactor path $\left(65^{\circ} \mathrm{C}\right)$.

\section{Copper phthalocyanine dye degradation}

Until entrance to the photo-reactor, the solution kept its original blue color, that is, the exposure time of the sample to the ${ }^{\circ} \mathrm{OH}$ radical generated in the Fenton reaction was not enough to start a significant color reduction of the dye. Four experiments were performed using a $20 \mu \mathrm{mol} \mathrm{L}^{-1}$ dye solution under distinct experimental conditions as detailed in Table 1. Results are graphically summarized in Figure 6. Phthalocyanine dye has a linear absorbance range from 1.0 to $10 \mu \mathrm{mol} \mathrm{L}^{-1}$; thus the original solution signal height (experiments \#1 and \#2) should be about 1.2 times higher than the observed height due to linearity loss. The purpose of the first two experiments is to show that UV irradiation is the main factor involved in color removal of the solution (experiments \#3 and \#4). Fenton reaction alone (experiment \#2) caused a slight reduction in the color of the original solution, but it was not efficient under analysis time. A very strong decrease of the analytical signal is observed when the photo-reactor is operating; if a low concentration of the dye solution (below $20 \mu \mathrm{mol} \mathrm{L}{ }^{-1}$ ) was used, the detector could not be

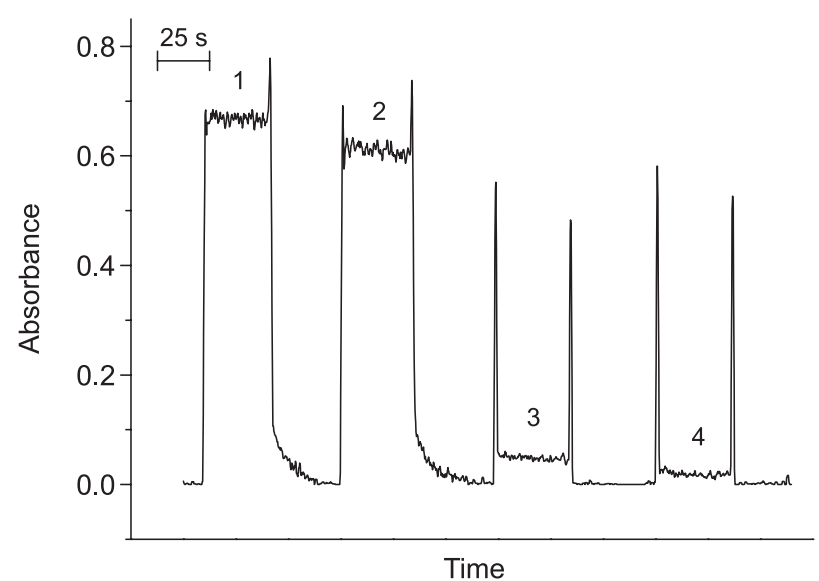

Figure 6. Grouped records of absorbance from tests of the photo-reactor on the degradation of $20 \mu \mathrm{mol} \mathrm{L}-1$ phthalocyanine blue dye solutions (from left to the right): (1) phthalocyanine solution with photo-reactor "off"; (2) - Fenton reaction mixture without UV irradiation; (3) - Fenton reaction mixture exposed to UV irradiation under $15 \mathrm{~s}$ of stopped flow period; (4) - Fenton reaction mixture exposed to UV irradiation under $30 \mathrm{~s}$ of stopped flow period.

able to register any signal from the remaining dye under operational conditions. Considering the calibration curve, the color removal percentage reached $97 \%$.

\section{Conclusions}

Preliminary tests have shown that the proposed photo-reactor could be used to study the degradation of matrices by the photo-Fenton reaction. It also suggests an industrially feasible pre-treatment process because fast color removal was achieved in a very short period of time, a feature that would not be possible by using only direct biological treatments ${ }^{11}$. Future works will show detailed study for phthalocyanine blue dye and how to get fast and reliable optimization of the degradation conditions with SIA manifolds. ${ }^{12}$

\section{Acknowledgements}

The authors are grateful to FAPESP and CNPQ for the financial support. We are also grateful to Carlos Eduardo Rodrigues da Silva and Juilson Nonato Machado da Silva for kindly helping to coat the photo-reactor. 


\section{References}

1. Huang, C. P.; Dong, C.; Tang, Z.; Waste Manage. 1993, 13, 361.

2. Nogueira, R. F. P.; Trovó, A. G.; da Silva, M. R. A; Vila, R. D.; Quim. Nova 2007, 30, 400.

3. Fenton, H. J. H.; J. Chem. Soc. 1894, 65, 899.

4. Pignatello, J. J.; Oliveros, E.; MacKay, A.; Crit. Rev. Environ. Sci. Technol. 2006, 36, 1.

5. Raj, C. B. C.; Quen, H. L.; Chem. Eng. Sci. 2005, 60, 5305.

6. Miró, M.; Hansen, E. H.; Trends Anal. Chem. 2006, 25, 267.

7. Ruzicka, J.; Marshall, G. D.; Anal. Chim. Acta 1990, 237, 329.

8. dos Santos, A. C. V.; Masini, J. C.; Talanta 2009, 77, 1081.
9. Cavicchioli, A.; Gutz, I. G. R.; Anal. Chim. Acta 2001, 445, 127.

10. Pasquini, C.; Oliveira, W. A.; Anal. Chem. 1985, 57, 2575.

11. Martínez, N. S. S.; Fernández, J. F.; Segura, X. F.; Ferrer, A. S.; J. Hazard. Mater. 2003, B101, 315.

12. dos Santos, A. C. V.; Masini, J. C.; Microchem. J. 2009, 93, 110.

Received: December 8, 2008

Web Release Date: October 9, 2009

FAPESP helped in meeting the publication costs of this article. 